\title{
QUEEN'S
UNIVERSITY
BELFAST
}

\section{Beta-adrenoceptor antagonists affect amyloid nanostructure; Amyloid hydrogels as drug delivery vehicles}

\author{
Mains, J., Lamprou, D. A., McIntosh, L., Oswald, I. D. H., \& Urquhart, A. J. (2013). Beta-adrenoceptor \\ antagonists affect amyloid nanostructure; Amyloid hydrogels as drug delivery vehicles. Chemical \\ Communications, 49(44), 5082-5084. https://doi.org/10.1039/C3CC41583J
}

\author{
Published in: \\ Chemical Communications
}

\section{Document Version:}

Peer reviewed version

Queen's University Belfast - Research Portal:

Link to publication record in Queen's University Belfast Research Portal

\section{Publisher rights}

(C) 2013 The Royal Society of Chemistry. This work is made available online in accordance with the publisher's policies. Please refer to any applicable terms of use of the publisher.

\section{General rights}

Copyright for the publications made accessible via the Queen's University Belfast Research Portal is retained by the author(s) and / or other copyright owners and it is a condition of accessing these publications that users recognise and abide by the legal requirements associated with these rights.

Take down policy

The Research Portal is Queen's institutional repository that provides access to Queen's research output. Every effort has been made to ensure that content in the Research Portal does not infringe any person's rights, or applicable UK laws. If you discover content in the Research Portal that you believe breaches copyright or violates any law, please contact openaccess@qub.ac.uk. 


\title{
Beta-Adrenoceptor Antagonists Affect Amyloid Nanostructure; Amyloid hydrogels as drug delivery vehicles
}

\author{
Jenifer Mains ${ }^{a}$, Dimitrios Lamprou ${ }^{a}$, Lisa McIntosh ${ }^{a}$, Iain Oswald ${ }^{a}$ and Andrew J. Urquhart*a \\ Received (in $X X X, X X X)$ Xth $X X X X X X X X X 20 X X$, Accepted Xth $X X X X X X X X X 20 X X$ \\ DOI: 10.1039/b000000x
}

Beta-adrenocepetor antagonists (beta-blockers) alter the nanostructure of lysozyme amyloids, resulting in different drug release profiles.

Hydrogels are water swollen gels with chemistries derived either ${ }_{10}$ from water soluble polymers ${ }^{1}$ or water soluble molecules ${ }^{2}$ that undergo self-assembly into long range fibres, thus forming a network (similar to a polymeric network). Hydrogels are an established family of drug carrier systems within drug delivery due to a number of reasons including pharmacokinetic release ${ }_{15}$ profiles and biocompatibility. ${ }^{1,3}$ There is a growing trend within pharmaceutics to explore the viability of both biological and biologically inspired hydrogels as drug delivery vehicles for a number of reasons, including improved biocompatibility, improved biodegradability and limited immunogenicity compared 20 to many synthetic materials..$^{4-8}$ Amyloid hydrogels are increasingly attracting attention as functional materials. .90 Amyloids are macromolecules comprised of amino acid sub-units with a secondary structure that is largely comprised of $\beta$-sheets, resulting in fibrils (when single stranded) or fibres (multiple ${ }_{25}$ strands) with diameters on the nanoscale. ${ }^{9}$ Amyloid hydrogels have been previously proposed as drug delivery vehicles but with an emphasis on peptide rather than small molecule delivery. ${ }^{11}$ Here we explore lysozyme amyloid hydrogels as drug delivery vehicles for a series of small molecule beta adrenoceptor 30 antagonists (atenolol, propranolol and timolol; Fig. S1). We report the influence of drug molecule chemistry on amyloid structure and how these changes influence drug release kinetics.

Drug loaded lysozyme amyloid hydrogels were prepared by mis-folding lysozyme in the presence of drug (see supplementary 35 information). The in-situ drug loading route is preferred in selfassembling systems over an ex-situ route (i.e. isolating amyloid fibres then drug loading) for a number of reasons including drug encapsulation issues, changes in vehicle nanostructure etc., 5, 7 Fig.1 shows the height images obtained for the drug loaded 40 amyloid hydrogels using atomic force microscopy (AFM). Atenolol loaded hydrogels (Fig.1A) show no amyloid fibril/fibre formation. Instead only large agglomerates (up to $100 \mu \mathrm{m}$ in diameter) comprised of spherical nanoparticles with an average diameter of $67.42 \mathrm{~nm}( \pm 30.66 \mathrm{~nm})$ are observed. In direct 45 contrast, propranolol loaded hydrogels (Fig. 1B and 1C) show extended fibres with diameters of $55.47 \mathrm{~nm}( \pm 20.34 \mathrm{~nm})$ and significant lengths ( $\sim 2-8 \mu \mathrm{m}$ for many fibres). Two distinct types of fibres can be seen in the propranolol loaded hydrogels: long
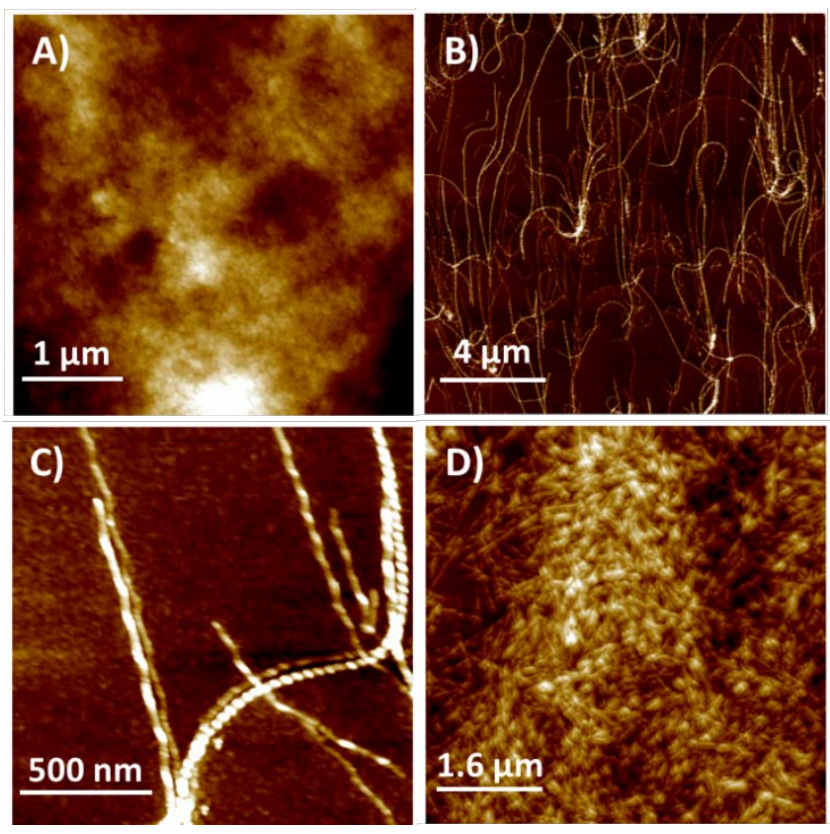

50 Fig.1 AFM height images of drug loaded amyloid hydrogels. (A) Atenolol loaded sample. (B) Propranolol loaded sample. (C) Propranolol loaded sample showing both LRP and SRP fibres. (D) Timolol loaded sample.

range periodicity (LRP) and short range periodicity (SRP) (Fig. ${ }_{55} \mathrm{~S} 2$ ). The ratio of two types (LRP:SRP) appears to be approximately 50:50. Changes in amyloid fibre periodicity have been previously reported and attributed to both $\beta$-sheet content ${ }^{12}$ and number of amyloid fibrils within a fibre. ${ }^{13}$ The SRP fibres show a periodicity of $35.70 \mathrm{~nm}( \pm 2.74 \mathrm{~nm})$, which is very similar 60 in periodicity to $\beta$-lactoglobulin amyloid fibrils with high $\beta$-sheet content (close to 100\%). ${ }^{12,13}$ The LRP fibres show a range of periodicities (between 90 and $150 \mathrm{~nm}$ ), which is likely to reflect varying - but lower than SRP - degrees of $\beta$-sheet content. ${ }^{12}$ Adamcik et al. used molecular dynamic simulations to show fibre 65 periodicity relating to fibril content with SRP occurring in fibres comprised of 2 fibrils and periodicity increasing with additional fibrils. ${ }^{13}$ Interestingly, for the propranolol loaded samples the LRP fibres had similar diameters to the SRP fibres indicating that both fibre types are comprised of 2 fibrils and that the drug 70 molecule and/or drug molecule concentration in a fibre is likely influencing $\beta$-sheet content. Timolol loaded hydrogels (Fig. 1D) 


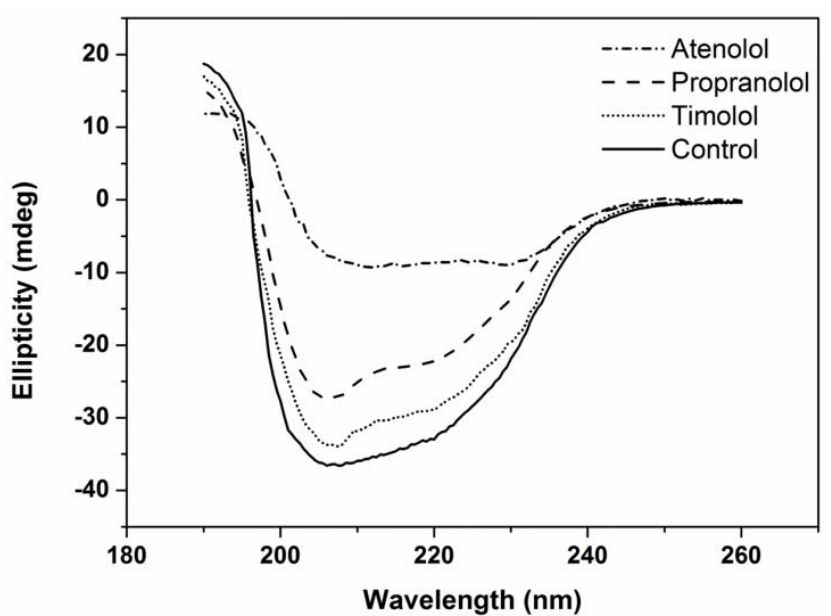

Fig.2 The CD spectra for drug loaded amyloid hydrogel. The control sample is non-loaded amyloid hydrogel.

produce shorter amyloid fibres (usually in the order of $200 \mathrm{~nm}$ in 5 length) than propranolol loaded but with similar widths (41.99 $\mathrm{nm} \pm 8.45 \mathrm{~nm}$ ). However, these fibres show little periodicity, a potential consequence of both short length scale and a mixed content between $\alpha$-helix and $\beta$-sheet compared to the propranolol loaded hydrogels. ${ }^{12}$ Equally, in the case for atenolol, the 10 nanoparticles likely reflect a mixture of $\alpha$-helix and $\beta$-sheet but with lower $\beta$-sheet content than either the propranolol and timolol systems.

Circular dichroism (CD) analysis of the drug loaded hydrogels reveals structural information which corroborates with the AFM 15 height images (Fig. 2). The CD spectra for the non-loaded amyloid hydrogel (added as a comparative aid) follows previously observed spectra and reflects the extended $\beta$-sheet structure of an amyloid. ${ }^{14,15}$ The spectra for both propranolol and timolol loaded amyloid hydrogels reveals extended $\beta$-sheet 20 structures, albeit with a more prominent peak at $208 \mathrm{~nm}$ than nonloaded amyloid hydrogels. ${ }^{14}, 15$ The CD spectra for the atenolol loaded amyloid hydrogel is significantly distinct from the three other systems, does not fit the profile of previously reported amyloid CD spectra ${ }^{14,15}$ but is close in profile to two reported CD 25 spectra for $A \beta(11-28)$ variants, Arctic E22G and Italian E22K albeit in a mixed solvent system. ${ }^{14}$ The atenolol spectra indicates less $\beta$-sheet content and a greater content of $\alpha$-helix compared to the other drug loaded systems, which is corroborated by the lack of observed fibres for the atenolol system. The Arctic E22G has 30 been previously reported to form large spherical nanoparticles 18$22 \mathrm{~nm}$ in diameter ${ }^{16}$ as have amyloid fibrils prepared on hydrophobic surfaces. ${ }^{17}$ The difficulty with atenolol is that it neither completely reflects the side chain chemistry of amino acids in $A \beta(11-28)$ variants nor is it the most hydrophobic of the 35 loaded drug molecules (i.e. propranolol, atenolol is most hydrophilic of the series of drugs). It is therefore likely that atenolol disrupts extended $\beta$-sheet formation more significantly than either propranolol or timolol.

Analysing the infrared (IR) amide I region (1600-1700 $\mathrm{cm}^{-1}$ ) of 40 the drug loaded amyloid hydrogels reveals differences between the systems (Fig. S3) consistent with both AFM image and CD spectra sample differences. The amide I region of non-loaded amyloid fibres (Fig. S3D) is dominated by five peaks: $1608 \mathrm{~cm}^{-1}$

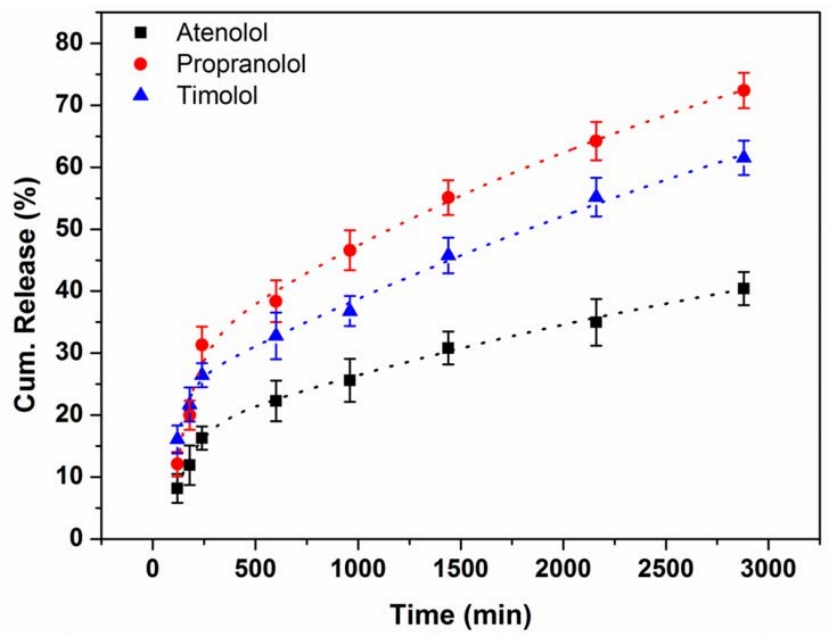

45 Fig.3 The cumulative release of drug over time data. The dashed lines show $2^{\text {nd }}$ order exponential fits.

(side chain moieties ${ }^{18}$ and/ or fibril structure contributions ${ }^{19}$ ); $1627 \mathrm{~cm}^{-1}, 1665 \mathrm{~cm}^{-1}, 1686 \mathrm{~cm}^{-1}\left(\beta\right.$-sheet contributions $\left.{ }^{18-20}\right)$ and $1646 \mathrm{~cm}^{-1}$ ( $\alpha$-helix contributions ${ }^{18-20}$ ). Propranolol loaded and 50 timolol loaded amyloid fibres show similar amide I profiles to non-loaded fibres but with slight differences in peak intensities (particularly the peaks associated with $\beta$-sheet contributions). Atenolol is the only drug molecule in this study with an amide moiety (Fig. S1), with three sharp amide I peaks at $1584 \mathrm{~cm}^{-1}$, $551612 \mathrm{~cm}^{-1}$ and $1635 \mathrm{~cm}^{-1}$ as well as a broad shoulder region beyond the $1635 \mathrm{~cm}^{-1}$ peak (Fig. S4). These three peaks coincide with either amyloid $\beta$-sheet contributions $\left(1588 \mathrm{~cm}^{-1}\right.$ and 1637 $\mathrm{cm}^{-1}$ ) or side chain moieties $\left(1616 \mathrm{~cm}^{-1}\right)$. However, taking this information into account, the atenolol loaded amyloid fibre 60 spectrum shows a higher proportion of $\alpha$-helix $\left(1642 \mathrm{~cm}^{-1}\right)$ compared to $\beta$-sheet $\left(1627 \mathrm{~cm}^{-1}\right.$ and $\left.1662 \mathrm{~cm}^{-1}\right)$.

Drug release profiles for all drug loaded systems (Fig. 3) show $2^{\text {nd }}$ order exponential release profiles, indicating a diffusion drug release mechanism (Fig. S5). The rate of release constants (k) 65 were $1.99 \times 10^{-6} \%^{-1} \mathrm{~min}^{-1}$, $4.87 \times 10^{-6} \%^{-1} \mathrm{~min}^{-1}$ and $8.34 \times 10^{-6} \%^{-}$ ${ }^{1} \mathrm{~min}^{-1}$ for atenonol $(\log \mathrm{P}=0.43)$, timolol $(\log \mathrm{P}=1.3)$ and propranolol ( $\log P=2.4$ ) loaded systems. Surprisingly, the rate of release constants obtained are inversely proportional to drug molecule partition coefficients, which is counterintuitive given 70 the predominantly hydrophilic environment of the amyloid hydrogels (equally it would not be unreasonable to assume hydrophobic molecules would prefer amyloid fibre cores to water exposed surfaces). The most plausible explanation for this phenomenon would be that the fibres observed in propranolol and 75 timolol loaded systems have a far higher surface area and smaller radii (therefore a shorter diffusion route for drug molecules) ${ }^{21}$ than the nanoparticles formed under atenolol loading. This is further exemplified by the propranolol release constant being larger than timolol corroborating with propranolol loaded 80 amyloid fibres having larger surface areas and smaller radii than timolol loaded amyloid fibres. Additionally, the agglomeration of atenolol loaded amyloid nanoparticles will also potentially inhibit drug diffusion.

The results presented here show that beta-adrenoceptor 85 antagonists significantly influence the nanostructure of amyloids. Atenolol disrupts $\beta$-sheet content and/or promotes $\alpha$-helix 
content, whilst propranolol promotes $\beta$-sheet content. Timolol appears to sit between the two with regards to $\beta$-sheet promotion. A tentative explanation for this observation would be that atenolol interacts with heavily hydrogen bond $\beta$-sheet surface of 5 the amyloid, disrupting extended hydrogen bonding and therefore $\beta$-sheet content. Atenolol is the most hydrophilic of the betaadrenoceptor antagonists used (lowest Log $\mathrm{P}$ value) and so would potential occupy the interface between amyloid and aqueous environment. Equally, propranolol is the most hydrophobic of the

10 drug series, would potential occupy the core of the amyloid and so not disrupt extended $\beta$-sheet structure. In this case the drug molecules can be viewed as either structure promoting cosmotropes (i.e. propranol and timolol) and structure disrupting kaotropes (i.e. atenolol), similar to ions in the Hofmeister series. ${ }^{22}$ 15 However, further work is required to determine drug molecule location within the amyloid fibre. This work also highlights that care must be taken when proposing self-assembled systems as drug delivery vehicles, as changes to physicochemical properties are likely to occur with changes in chemical environment. There 20 is, however, the added possibility that - with careful selection of structure promoters and disruptors - drug delivery vehicle architecture can be controlled to obtain desirable release profiles.

\section{Notes and references}

${ }^{a}$ Strathclyde Institute of Pharmacy and Biomedical Sciences, 25 University of Strathclyde, 161 Cathedral Street, Glasgow, G4 ORE, UK. Fax: +44 141552 2562; Tel: +44 141548 5947; E-mail: andrew.urquhart@strath.ac.uk

$\dagger$ Electronic Supplementary Information (ESI) available: Experimental details and supplementary figures. See DOI: 10.1039/b000000x/

$30 \ddagger \mathrm{IO}$ and AU would like to acknowledge financial support from Tenovus Scotland.

1 A. Name, B. Name and C. Name, Journal Title, 2000, 35, 3523; A. Name, B. Name and C. Name, Journal Title, 2000, 35, 3523.

35 1. T. R. Hoare and D. S. Kohane, Polymer, 2008, 49, 1993-2007.

2. M. Zelzer and R. V. Ulijn, Chemical Society Reviews, 2010, 39, 3351-3357.

3. N. A. Peppas, P. Bures, W. Leobandung and H. Ichikawa, European Journal of Pharmaceutics and Biopharmaceutics, 2000, 50, 27-46.

40

4. A. Altunbas, S. J. Lee, S. A. Rajasekaran, J. P. Schneider and D. J. Pochan, Biomaterials, 2011, 32, 5906-5914.

5. E. L. Bakota, Y. Wang, F. R. Danesh and J. D. Hartgerink, Biomacromolecules, 2011, 12, 1651-1657.

45 6. R. Huang, W. Qi, L. Feng, R. Su and Z. He, Soft Matter, 2011, 7, 6222-6230.

7. S. Koutsopoulos and S. Zhang, Journal of Controlled Release, 2012, 160, 451-458.

8. R. E. Miller, P. W. Kopesky and A. J. Grodzinsky, Clinical

50 Orthopaedics and Related Research, 2011, 469, 2716-2724.

9. T. P. J. Knowles, T. W. Oppenheim, A. K. Buell, D. Y. Chirgadze and M. E. Welland, Nature Nanotechnology, 2010, 5, 204-207.

10. S. K. Maji, D. Schubert, C. Rivier, S. Lee, J. E. Rivier and R. Riek, Plos Biology, 2008, 6, 240-252.

55 11. S. Mankar, A. Anoop, S. Sen and S. K. Maji, Nano reviews, 2011, 2.

12. C. C. vandenAkker, M. F. M. Engel, K. P. Velikov, M. Bonn and G. H. Koenderink, Journal of the American Chemical Society, 2011, 133, 18030-18033.
13. J. Adamcik, J.-M. Jung, J. Flakowski, P. De Los Rios, G. Dietler and

60 R. Mezzenga, Nature Nanotechnology, 2010, 5, 423-428.

14. P. Juszczyk, A. S. Kolodziejczyk and Z. Grzonka, Acta Biochimica Polonica, 2005, 52, 425-431.

15. P. McPhie, Biopolymers, 2004, 75, 140-147.

16. H. A. Lashuel, D. M. Hartley, B. M. Petre, J. S. Wall, M. N. Simon,

65 T. Walz and P. T. Lansbury, Journal of Molecular Biology, 2003, 332, 795-808.

17. B. Moores, E. Drolle, S. J. Attwood, J. Simons and Z. Leonenko, Plos One, 2011, 6.

18. P. Roach, D. Farrar and C. C. Perry, Journal of the American $70 \quad$ Chemical Society, 2005, 127, 8168-8173.

19. L. Z. Polzi, A. Amadei, M. Aschi and I. Daidone, Journal of the American Chemical Society, 2011, 133, 11414-11417.

20. P. Juszczyk, A. S. Kolodziejczyk and Z. Grzonka, Journal of Peptide Science, 2009, 15, 23-29.

75 21. C. L. He, Z. M. Huang, X. J. Han, L. Liu, H. S. Zhang and L. S. Chen, Journal of Macromolecular Science Part B-Physics, 2006, 45, 515-524.

22. S. Roy, N. Javid, P. W. J. M. Frederix, D. A. Lamprou, A. J. Urquhart, N. T. Hunt, P. J. Halling and R. V. Ulijn, Chemistrya European Journal, 2012, 18, 11723-11731. 